RESEARCH ARTICLE

\title{
Effects of diazinon on survival and growth of two amphibian larvae
}

\author{
D.M. Sumanadasa ${ }^{1}$, Mayuri R. Wijesinghe ${ }^{2^{*}}$ and W.D. Ratnasooriya ${ }^{2}$ \\ Molecular Medicine Unit, Faculty of Medicine, University of Kelaniya, P.O. Box 6, Thalagolla Road, Ragama. \\ 2 Department of Zoology, Faculty of Science, University of Colombo, Colombo 03.
}

\begin{abstract}
Amphibian populations are declining globally at an alarming rate and evidence suggests that pesticides may be a principal cause. The present study investigated the effects of diazinon on the survival and growth of larvae of two amphibians, Bufo melanostictus (Asian common toad) and the Sri Lankan endemic Polypedates cruciger (Common hourglass frog).
\end{abstract}

Larvae were laboratory bred from egg clutches collected from ponds and wells in home gardens in the Gampaha and Colombo districts. Two separate trials were conducted using gill stage hatchlings (Gosner stages 20-22) of each species. The larvae were repeatedly exposed to $4 \mu \mathrm{g} / \mathrm{L}, 400 \mu \mathrm{g} / \mathrm{L}$ and $10 \mathrm{mg} / \mathrm{L}$ of diazinon for seven days. Results showed that exposure to $10 \mathrm{mg} / \mathrm{L}$ of diazinon caused significant elevations $(\mathrm{p}<0.05)$ in larval mortality in both $B$. melanostictus and $P$. cruciger as compared to the controls. No significant increases in mortality were noted at $4 \mu \mathrm{g} / \mathrm{L}$ and $400 \mu \mathrm{g} / \mathrm{L}$. The trends in mortality were significant and positive for both species. Growth retardation was also noted at the highest dose of $10 \mathrm{mg} / \mathrm{L}$, these larvae being significantly smaller than those in the controls $(\mathrm{p}<0.05)$. Larval activity was also seriously impaired at the highest dose.

Keywords: Amphibian, Bufomelanostictus, diazinon, mortality, organophosphate pesticide, Polypedates cruciger, tadpoles

\section{INTRODUCTION}

The widespread application of pesticides has attracted the attention of ecologists due to the impacts of these chemicals on natural communities. A diversity of pesticides and their residues are present in a variety of aquatic habitats ${ }^{1}$. While pesticides have the potential to affect many types of aquatic organisms, amphibian larvae are especially sensitive because of their permeable skin and gills ${ }^{2}$. Not surprisingly, pesticides have been identified as one of the major causes of amphibian declines worldwide ${ }^{3-6}$.

Sri Lanka, with about $2 \%$ of the world's amphibian fauna, has been recognized as a global amphibian hotspot. The island supports more than a hundred species, of which 88 are found nowhere else in the world 7 . The majority of these amphibians, especially the endemics, are restricted to the southwestern rainforests that are mostly surrounded by agricultural plantations. Although no data are yet available on population trends of Sri Lankan amphibians, it is clear that many species have undergone range reductions or population declines in the last decade. It is of significance that about $70 \%$ of the island's amphibians are currently facing the threat of extinction? ${ }^{7}$. The expansion of agriculture and horticultural industries in the country and the accompanying increase in the use of pesticides ${ }^{8}$ have been implicated as probable causes for the threatened status of many of these amphibian species $^{7}$. Despite the widely held belief that pesticides are responsible for amphibian declines in Sri Lanka, there is a dearth of empirical evidence to justify these claims.

To understand the role of pesticides in causing amphibian decline, it is necessary to first study their direct toxicity through empirical studies ${ }^{9-11}$. The present study was aimed at providing evidence for the potential toxic impacts of a widely used organophosphate pesticide, diazinon, on the growth and survival of the larvae of two amphibian species, the common toad Bufo melanostictus and the endemic common hourglass frog Polypedates cruciger. Apart from a preliminary study on the effect of chlorpyrifos on Rana sp. ${ }^{12}$, there are no reports of investigations on the effects of pesticides on endemic amphibian species in Sri Lanka. 


\section{MATERIALS AND METHODS}

In February and March 2006, six egg masses, three from each of the two species B. melanostictus and P. cruciger, were collected from ponds and wells in home gardens, in Delgoda and Malabe in the Districts of Gampaha and Colombo. The egg masses were identified as belonging to the study species by their external morphology as described by Kirthisinghe $(1955)^{13}$. The egg masses were left to hatch under natural light conditions (approximately $12 \mathrm{~h}$ day light).

Three concentrations of diazinon, $4 \mu \mathrm{g} / \mathrm{L}, 400 \mu \mathrm{g} / \mathrm{L}$, and $10 \mathrm{mg} / \mathrm{L}$, were selected for the exposure trials. This selection was based on experiments conducted elsewhere ${ }^{14}$. As the application dose of diazinon is in the range of $1000 \mathrm{mg} / \mathrm{L}$ (as per instructions), it was also considered necessary to test toxicity at a high dose. Commercial grade diazinon purchased from Baurs Ltd. Colombo was used to prepare the selected test concentrations of pesticide. All experiments were conducted at ambient temperature and under natural light conditions. Separate sets of experiments were conducted for the two species. Glass tanks of $25 \times 25 \times 15 \mathrm{~cm}$ containing 2 liters of tap water were used for the exposures. Tap water was initially collected into buckets and left for $24 \mathrm{~h}$ to allow chlorine levels to reduce. Preliminary investigations revealed that tadpoles of $B$. melanostictus and $P$. cruciger survived well in this water. Subsequently, eighteen hatchlings of a given species (6 from each clutch $\mathrm{x} 3$ clutches) corresponding to Gosner stages $20-22^{15}$ were randomly assigned to each tank. The relevant pesticide concentrations were then added and the water was mixed using a glass rod. Each treatment and the controls (without pesticides) were maintained in triplicate. The water was changed and pesticide concentrations were renewed once (after three days) during the 7-d trial period. Previous studies conducted with pesticides following a similar methodology, but with water renewal being carried out every five days ${ }^{16}$, has shown less than $25 \%$ deviations in pesticide levels. The larvae were fed once a day on fish food pellets (Qualitypets Aquatics, Ja-Ela). Fifty pellets $(0.048 \pm 0.005 \mathrm{~g})$ were added daily to each tank. The temperature and $\mathrm{pH}$ were measured in each tank using a thermometer (Brannan, Lloyd's register company, North Carolina, U.K.) and pH meter (TOA HMV30v, Tokyo). The water temperature varied between $27.3{ }^{\circ} \mathrm{C}$ and $28.0^{\circ} \mathrm{C}$ and $\mathrm{pH}$ between 7.2 and 7.9 with no statistical difference in water temperature or $\mathrm{pH}$ being detected between and within the treatments and replicates.

Larval mortality was monitored daily. The body length (from the tip of the snout to anus) was measured at the end of the 7-d exposure using a vernier caliper (Dialmax Spi
2000, Switzerland). The activity levels of the larvae were also recorded on the $7^{\text {th }}$ day after the initial exposure. For this, two lines (one vertical and the other horizontal along the mid lines) were drawn on a white sheet of paper and each glass tank was placed on this paper. The tanks were observed from above and the numbers of crossings by the tadpoles were counted for $10 \mathrm{~min}$.

To assess the effect of diazinon on mortality, a one-way ANOVA was performed using total percentage mortality (square-root transformed), length or activity at the end of the exposure period as the dependent variable and the pesticide concentration as the categorical variable. The activity levels of the larvae were calculated by dividing the total number of crossings observed per tank by the number of larvae in the tank at the time of observation. In all cases, the post-hoc HSD Tukey tests were used for pair-wise comparisons. Dose-dependency was examined with the Pearson's correlation test using the total mortality values of the two species.

\section{RESULTS}

The results show that diazinon causes marked increases in the levels of larval mortality in both species of amphibians (Figure 1). A highly significant elevation in larval mortality (11\% in B. melanostictus and $10 \%$ in $P$. cruciger) was evident at the highest tested dose of $10 \mathrm{mg} / \mathrm{L}$ in both amphibian species (B. melanostictus $\mathrm{F}=5.71, \mathrm{p}<0.01 ;$ P. cruciger $\mathrm{F}=11.48, \mathrm{p}<0.01)$. The mortality levels also correlated positively with the magnitude of the dose (B. melanostictus $\mathrm{r}=0.99$, $\mathrm{p}<0.001 ;$ P. cruciger: $\mathrm{r}=0.95, \mathrm{p}<0.05)$. No larval deaths occurred in the controls or in larvae treated with $4 \mu \mathrm{g} / \mathrm{L}$ of diazinon in both species during the 7-day exposure period. A concentration of $400 \mu \mathrm{g} / \mathrm{L}$ was not detrimental to the larvae of $B$. melanostictus but resulted in low levels of mortality (3.4\%) in P. cruciger.

In addition to mortality, diazinon also caused growth retardation in larvae of both amphibian species. The length of tadpoles treated with $10 \mathrm{mg} / \mathrm{L}$ were significantly lower than those in the control tanks (one-way ANOVA: B. melanostictus $\mathrm{F}=4.66, \mathrm{p}<0.05 ;$ P. cruciger $\mathrm{F}=16.69$, $\mathrm{p}<0.001)$. No significant reductions in length were evident in larvae exposed to $4 \mu \mathrm{g} / \mathrm{L}$ and $400 \mu \mathrm{g} / \mathrm{L}$. Results also showed that there was a significant reduction in larval activity in both $B$. melanostictus and $P$. cruciger by the seventh day (one-way ANOVA: $B$. melanostictus $\mathrm{F}=99.18, \mathrm{p}<0.05 ;$ P. cruciger $\mathrm{F}=151.58, \mathrm{p}<0.05)$. The impairment of activity was severe with a $40 \%$ reduction in larval activity being noted for $B$. melanostictus treated with $10 \mathrm{mg} / \mathrm{L}$ of diazinon as compared to the control. The retardation of activity was even greater for $P$. cruciger 


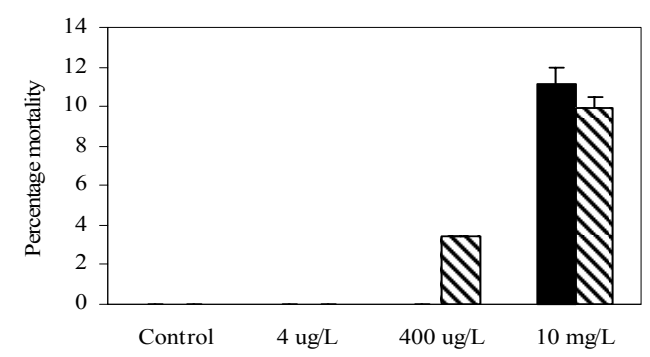

Figure 1: Mean percentage mortality $( \pm$ S.E) in gill-stage hatchlings of B. melanostictus (solid bars) and P. cruciger (hatched bars) exposed to diazinon for seven days. Values are based on three replicates $(n=18$ per replicate). Absence of bars indicates zero mortality.

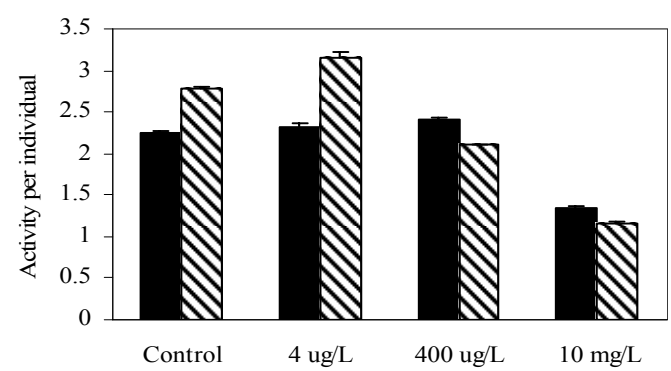

Figure 3: Mean activity levels of gill-stage hatchlings of $B$. melanostictus (solid bars) and P. cruciger (hatched bars) after exposure to diazinon for seven days. Values are based on three replicates ( $\mathrm{n}=18$ per replicate).

with a $60 \%$ reduction as compared to the controls. No significant alteration in activity was noted at the lower doses of 4 and $400 \mu \mathrm{g} / \mathrm{L}$.

\section{DISCUSSION}

The present study provides clear empirical evidence for the adverse effects of a commonly used organophosphate pesticide on the larval stages of two amphibian species in Sri Lanka indicating that such agrochemicals may at least in part contribute to the recorded declines of these species in the country. It was evident that short term exposure to $10 \mathrm{mg} / \mathrm{L}$ of diazinon caused significant elevations in larval mortality in B. melanostictus and P. cruciger. The toxic effects of diazinon are mainly due to the metabolite diazoxon that is formed in animals. Diazoxon is a potent enzyme inhibitor capable of killing tadpoles directly by inhibiting acetylecholinesterase and numerous other important enzymes with molecular structures that are similar to it ${ }^{17}$. Both the tested species suffered near-similar toxicities at the highest dose of $10 \mathrm{mg} / \mathrm{L}$. However, interspecific differences in diazinon toxicity have been noted in other studies. A LC50 value of

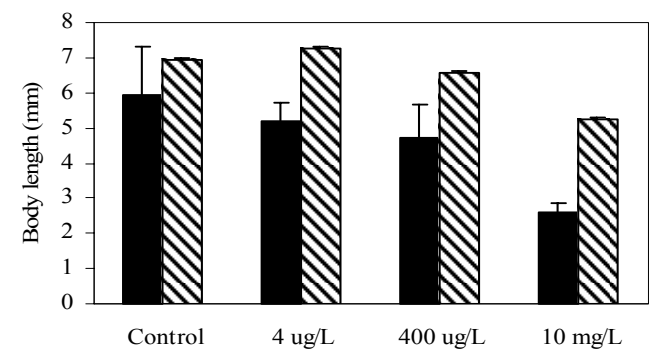

Figure 2: Mean body length $( \pm$ S.E) of gill-stage hatchlings of $B$. melanostictus (solid bars) and P. cruciger (hatched bars) exposed to diazinon for seven days. Values are based on three replicates $(\mathrm{n}=18$ per replicate).

$14 \mathrm{mg} / \mathrm{L}$ for diazinon has been reported for Bufo bufo ${ }^{18}$, while a LC50 value of $5 \mu \mathrm{g} / \mathrm{L}$ has been obtained for the same pesticide in the case of Rana clamitans ${ }^{19}$. Such interspecific differences in pesticide toxicity have been attributed to factors such as the variation in the age and duration of the exposure ${ }^{20,21}$. Interspecific differences in susceptibility to pesticides could be also due to differential rates of absorption through the skin and variation in the ability to detoxify chemicals ${ }^{22}$. No LC50 values were calculated in this study since the range of concentrations tested did not cause $50 \%$ mortality in the larvae of the two studied species.

Diazinon also impaired the growth of the larvae of the two study species. Growth retardation in organisms exposed to pesticides could be due to decreased activity ${ }^{22}$ ultimately affecting food intake of the exposed animals. Additionally, the higher rate of metabolism displayed by animals exposed to environmental stressors such as pesticides may also result in reduced weight gain ${ }^{23}$. A smaller size is related to lower survival and fecundity and a lesser ability to compete for food ${ }^{24}$. This implies that exposure to pesticides might ultimately result in repeated failure to recruit juveniles to populations thereby facilitating their extinction. The slight increase in body size and activity in $P$. cruciger larvae exposed to $4 \mu \mathrm{g} / \mathrm{L}$ as compared to the control, is probably due to a growth stimulatory effect induced by some contaminants at low doses ${ }^{25}$.

The magnitude of the impact of pesticide exposure on an amphibian species depends greatly on its biological attributes. Bufonids and some aquatic ranids that breed in shallow ponds or streams may be exposed to agrochemicals during both the egg and larval stage. On the other hand, rhacophorids that use arboreal habitats to breed may be exposed to aquatic pollutants only during their aquatic larval phase. Totally terrestrial species such as the philotids would be far less affected by aquatic contaminants. In addition to the direct effects 
on amphibian larvae the widespread application of pesticides poses a direct threat to adults, as they traverse across agricultural landscapes in search of breeding sites. Pesticides may also severely affect adults by drastically reducing the availability of their arthropod prey ${ }^{14}$.

This study has shown that diazinon causes larval death and the impairment of growth and activity in the two tested amphibian species at a dosage of $10 \mathrm{mg} / \mathrm{L}$. This is indeed alarming given that the recommended dose for spraying diazinon in Sri Lanka is in the range of 1000 $\mathrm{mg} / \mathrm{L}$. This finding further emphasizes the importance of considering both lethal and sub lethal effects of pesticides on non-target organisms like amphibians that are integral components of natural ecosystems. This is of particular concern in Sri Lanka where pesticides are repeatedly applied at concentrations well above the recommended levels. While the protection of amphibians depends on a global commitment to control the use of toxic chemicals, well-targeted research can also make a significant contribution towards amphibian conservation. This is particularly relevant to a country like Sri Lanka which has an agriculturally based economy and a wide diversity of amphibians.

\section{Acknowledgement}

The Department of Zoology, University of Colombo is gratefully acknowledgement for providing funds and equipment to carry out this project. Technical officers Ms. Anoma de Silva and Mr. J. R. A. C. Jayakody of the Department of Zoology and Mr. Kapila Fernando of the Department of Chemistry are also thanked for their assistance throughout the project.

\section{References}

1. McConnell L.L., LeNoir J.S., Datta S. \& Seiber J.N. (1998). Wet deposition of current-se pesticides in the Sierra Nevada Mountain range, California, USA. Environmental Toxicology and Chemistry 17:1908-1916.

2. Duellman W. \& Trueb L. (1986). Biology of Amphibians. Johns Hopkins University Press, Baltimore, USA.

3. Blaustein A.R. \& Wake D.B. (1990). Declining amphibian populations: a global phenomenon? Trends in Ecology and Evolution 5:203-204.

4. Alford R.A. \& Richards S.J. (1999). Global amphibian declines: a problem in applied ecology. Annual Review of Ecology and Systematics 30:133-165.

5. Houlihan J.E., Findlay C.S., Schmidt B.R., Meyers A.H. \& Kuzmin S.L. (2001). Quantitative evidence for global amphibian population declines. Nature 404:752-755.

6. Kiesecker J.M., Blaustein A.R. \& Belden L.K. (2001). Complex causes of amphibian population declines. Nature 410:681-684.
7. Pethiyagoda R., Manamendra-Arachchi K., Bahir M.M. \& Meegaskumbura M. (2006). Sri Lankan amphibians: Diversity, uniqness and conservation. In: The fauna of Sri Lanka. Status of taxonomy, research and conservation. (Ed. C.N.B. Bambaradeniya) pp. 216-231. The World Conservation Union, Colombo.

8. Food and Agricultural Organization (1991). International code of conduct on the distribution and use of pesticides. Food and Agricultural Organization, Rome, Geneva.

9. Mann R.M. \& Bidwell J.R. (1999). The toxicity of glyphosate and several glyphosate formulations to four species of southwestern Australian frogs. Archives of Environmental Contamination and Toxicology 26:193199.

10. Perkins P.J., Boermans H.J. \& Stephenson G.R. (2000). Toxicity of glyphosate and triclopyr using the frog embryo teratogenesis assay-Xenopus. Environmental Toxicology and Chemistry 19:940-945.

11. Fordham C.L., Tessari J.D., Ramsdell H.S. \& Keefe T.J. (2001). Effects of malathion on survival, growth, development, and equilibrium posture on bullfrog tadpoles (Rana catesbeiana). Environmental Toxicology and Chemistry 20:179-184.

12. Samayawardhane L., Chandana S.E., Peiris, D.L.D. \& Dharmasiri H. (2001). Can environmentally available pesticide concentrations affect frog larvae? A study with JUDO50 (Chlopyrofos). Proceedings of Environmental Toxicology and Chemistry 5: 329-340.

13. Kirthisinghe P. (1955). The amphibians of Ceylon, first edition, Charles Circus, Colombo.

14. Relyae R.A. (2005). Pesticides and amphibians: the importance of community context. Ecological Applications 15:1118-1124.

15. Gosner K.L. (1960). A simplified table for staging anuran embryos and larvae with notes on identification. Herpetological Science 16:183-190.

16. Storrs S.I. \& Kiesecker J.M. (2004). Survivorship patterns of larval amphibians exposed to low concentrations of atrazine. Environmental Health Perspective 112(10): 1054-1057.

17. Colombo A., Orsi F. \& Patrizia Bonfanti P. (2005). Exposure to the organophosphorus pesticide chlropyrofos inhibits acetylcholinesterase activity and effects of muscular integrity in Xenopus laevis larvae. Chemosphere 61: $1665-1671$.

18. Hashimoto Y. \& Nishiuchi Y. (1981). Establishment of bioassay methods for the evaluation of acute toxicity of pesticides to aquatic organisms. Japanese Journal of Pesticide Science 6:257-264.

19. Harris M.L., Bishop C.A., Struger J., Ripley B. \& Bogart J.P. (1998). The functional integrity of Northern Leopard Frog (Rana pipiens) and Green Frog (Rana clamitans) populations in Orchard Wetlands. Environmental Toxicology and Chemistry 17(7):1351-1363.

20. Ortiz M.E., Marco A., Saiz N. \& Lizana M. (2004). Impact of ammonium nitrate on growth and survival of six European amphibians. Archives of Environmental Contamination and Toxicology 47 (2): 234-239. 
21. Lajmanovich. R.C., Izaguirrem M.F. \& Casco V.H. (1998). Paraquat tolerance and alteration of internal gill structure of Scinax nasica tadpoles (Anura : Hylidae). Archives of Environmental Contamination and Toxicology 34: 364-369.

22. Marco A.Q. \& Blaustein A.R. (1999). Sensitivity to nitrate and nitrite in pond-breeding amphibians from Pacific Northwest. Environmental Toxicology and Chemistry 18: 2829-2836.

23. Rowe C.L., Kinney O.M., Nagle R.D. \& Congdon J.C.
(1998). Elevated maintenance costs in an anuran (Rana catesbeiana) exposed to a mixture of trace elements during the embryonic and early larval periods. Physiology of Zoolgy 71: 27-35.

24. Smith D.C. (1987). Adult recruitment in chorus frogs: effects of size and date at metamorphosis. Ecology 68: 344-350.

25. Bailer A.J., Oris J.T., See K., Hughes M.R. \& Schaefer R. (2003). Defining and evaluating impact in environmental toxicology. Environmetrics 14:235-243. 